\title{
NHÂN MỘT TRƯờNG HợP \\ DỊ DẠNG THÔNG ĐỘNG TĨNH MẠCH PHỔI Ở TRẺ EM
}

ThS.BS. Thái Việt Tuấn*

\section{TÓM TĂT}

Dị dạng thông động tĩnh mạch phổi là một bệnh lý hiếm gặp ở trẻ em do nối thông trực tiếp giữa động mạch và tĩnh mạch phổi, không qua mạng lưới mao mạch phổi, tạo nên luồng thông phải trái. Đây là môt nguyên nhân hiếm gặp gây nên tím trung ương ở trẻ em, và dễ bị bỏ sót trong chẩn đoán. Biểu hiện lâm sàng thường xuất hiện muộn với khó thở khi gắng sức, tím hoặc ngón tay ngón chân hình dùi trống. Chúng tôi giới thiệu một trường hợp lâm sàng dị dạng thông động tĩnh mạch phổi ở trẻ em được chẩn đoán và điều trị thành công tại Trung tâm Tim mạch Bệnh viện Trung ương Huế.

\section{ABSTRACT}

Pulmonary ateriovenous malformation is a rare condition in children in which there is direct abnormal connection between pulmonary arteries and veins, bypassing the normal pulmonary capillary bed, forming the right to left shunt. This is a rare cause of central cyanosis in children, easy to omit the diagnosis. The disorder usually appears in late childhood with dyspnea on exertion, cyanosis or clubbing. We present a case of pulmonary ateriovenous malformation in children discovered and treated successfully in Hue Cardiovascular Centre of Hue Central Hospital.

\section{ĐẶT VẤN ĐỀ}

Dị dạng thông động tĩnh mạch phổi do sự nối thông trực tiếp giữa động mạch và tĩnh mạch phổi gây ra. Đây là bệnh lý hiếm gặp ở trẻ em, chiếm tỉ lệ chỉ 2-3 trường hợp trong 1 triệu dân [2]. Hơn $80 \%$ trường hợp dị dạng thông động tĩnh mạch phổi là do bẩm sinh [3]. Biểu hiện lâm sàng thường dễ nhầm với bệnh cảnh tim bẩm sinh có tím như tứ chứng Fallot. Nếu không chẩn đoán sớm và điều trị kịp thời thì có thể xảy ra những biến chứng do luồng shunt phải trái gây nên, đặc biệt là bệnh cảnh nặng nề của đột qụy hay abscess não. Chúng tôi giới thiệu một trường hợp lâm sàng dị dạng thông động tĩnh mạch phổi ở trẻ em có biến chứng abscess não được điều trị tại Bệnh viện Trung ương Huế.

\section{TRƯÒ̀NG HỘP LÂM SÀNG}

Bệnh nhân Vương Tấn N, sinh ngày 19/09/2006, trẻ sinh thường, đủ tháng, con thứ 2 trong gia đình, và không có tiền sử gia đình về bệnh dãn mạch máu xuất huyết di truyền.

Người nhà phát hiện trẻ bị tím môi và đầu chi lúc trẻ được 1 năm tuổi. Trẻ được đưa đi khám cơ sở y tế và được chẩn đoán là bệnh tim bẩm sinh nhưng không rõ loại. Do gia đình có hoàn cảnh khó khăn nên họ không có điều kiện cho trẻ chửa trị và đã để trẻ ở nhà.

Cuối tháng 5 năm 2011, trẻ xuất hiện sốt cao, đau đầu và kèm nôn mữa. Lúc đó, trẻ được đưa vào bệnh viện tuyến dưới và được chẩn đoán là abcess não nhiều ổ/Tim bẩm sinh. Trẻ được điều trị kháng sinh Vancomycin + Metronidazole và chuyển Bệnh viện Trung ương Huế.

Ghi nhận lúc vào bệnh viện Trung ương Huế: trẻ tỉnh táo, thở mệt khi gắng sức, tím môi và đầu chi, ngón tay và chân hình dùi trống, thổi tâm thu $2 / 6$ ở gian sườn 3 trái, $\mathrm{SpO} 2$ : 82\% .

Một ngày sau, trẻ xuất hiện co giật cục bộ nữa người bên phải, liệt mặt trái, giật cục bộ ở tay, tím môi, sốt cao 39.3 độ C. Trẻ được chụp CT Scan và xác định abcess não đa ổ. Trẻ được chuyển mổ cấp cứu cùng ngày, lấy ra $200 \mathrm{ml}$ dịch mủ vàng đục, sánh. Sau mổ, trẻ được cho dùng kháng sinh: Vancomycin, Ceftriaxone, Metronidazole, tình trạng thần kinh ổn dần, giảm và hết liệt nữa người phải, đi lại được.

(*) Trung tâm Tim mạch-Bệnh viện Trung ương Huế Người chịu trách nhiệm khoa họ: GS.TS Bùi Đức Phú

Email: buiducphu@gmail.com

Ngày nhận bài: 10/04/2013

Ngày Cho Phép Đăng: 18/04/2013

Phản Biện Khoa học: PGS.TS. Lê Ngọc Thành, GS.TS.Bùi Đức Phú 


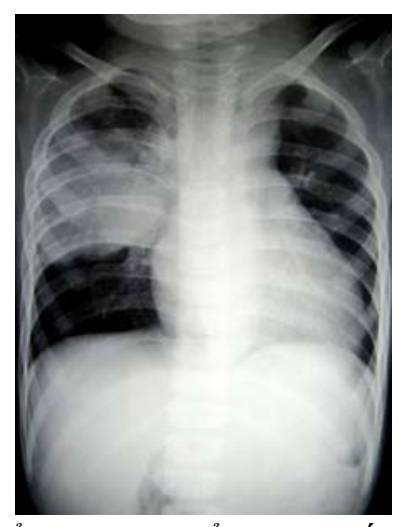

Hình 1: Xquang phổi không chuẩn bị - Khối mờ 1/3 giũa phổi phải

Hình ảnh Xquang phổi không chuẩn bị cho thấy hình ảnh khối mờ ở $1 / 3$ thùy giữa phổi phải, bóng tim lớn nhẹ.

Siêu âm tim qua thành ngực cho thấy cấu trúc và chức năng tim bình thường, không có luồng thông trong tim, dãn nhẹ thất trái. Tuy nhiên, siêu âm cản quang phát hiện có luồng thông phải trái nhiều.

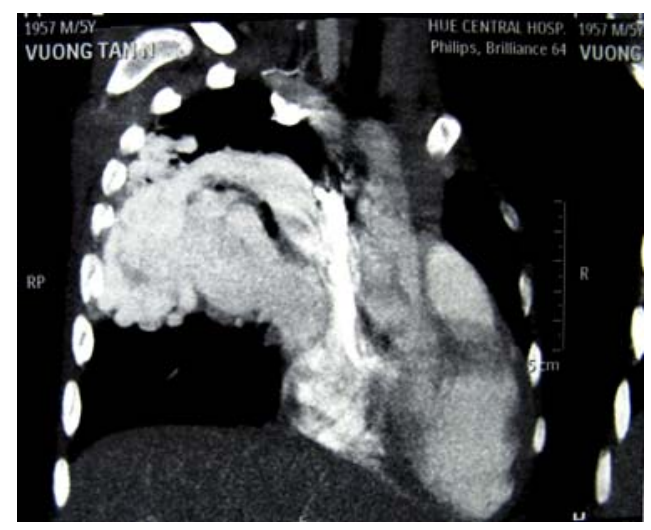

Điều này chứng tỏ trẻ có dị dạng thông động tĩnh mạch phổi hoặc dò động mạch phổi vào nhĩ trái.

Hình ảnh CT64 có bơm thuốc cho thấy hình dị dạng thông động tĩnh mạch phổi lớn ở giữa phổi phải, kích thước khối dị dạng 54 x 58 x 57 mm.

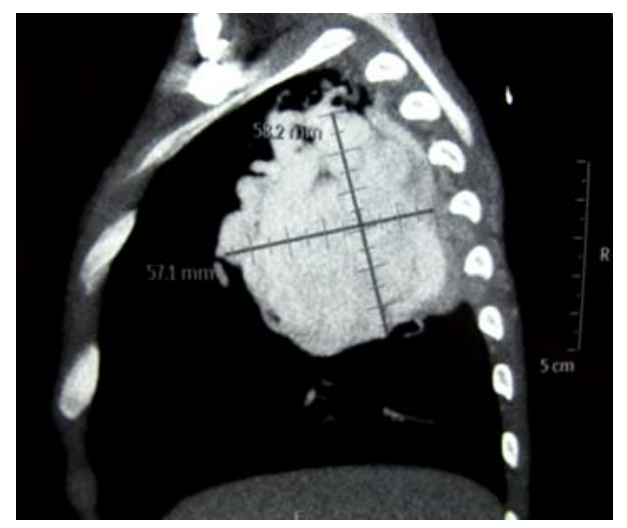

Hình 2 và 3: Hình ảnh CT64 phát hiện dị dạng thông động tĩnh mạch phổi

Bệnh nhi được phẩu thuật thắt động mạch đến của khối di dạng động tĩnh mạch phổi. Hậu phẩu: trẻ hồng lên, SpO2: 95-97\%, siêu âm cản quang kiểm tra không còn thấy luồng shunt phải trái.

Trẻ được xuất viện trong tình trạng sức khỏe tốt.

\section{BÀN LUẬN}

Dị dạng thông tĩnh mạch phổi được Churton phát hiện đầu tiên vào năm 1897 , tiếp đó là Wilkins năm 1937, và Rodes năm 1938 [8]. Tỉ lệ nam/nữ là $1 / 1.5$ đến 1.8. Tuổi phát hiện dao động từ sơ sinh đến 70 tuổi, tuy nhiên đa số trường hợp được chẩn đoán trong vòng 30 năm đầu đời sống. Dị dạng thông tĩnh mạch phổi có thể gặp đơn lẻ hoặc nhiều vị trí khác nhau ở phổi, tỷ lệ đơn lẻ chiếm 42 đến $74 \%$. Vị trí hay gặp nhất là thùy dưới phổi trái, kế đến là thùy dưới phải, thùy trên trái, thùy giữa phải và cuối cùng là thùy trên phải [3]. Hầu hết là do bẩm sinh, thường có liên quan đến bệnh lý dãn mạch xuất huyết di truyền, là một bệnh di truyền trội trên nhiễm sắc thể thường [4]. Sự nối thông bất thường động tĩnh mạch phổi có thể gặp trong một số bệnh mắc phải như sau chấn thương ngực, phẩu thuật Fontan, Glenn, xơ gan lâu ngày, hẹp van 2 lá, bệnh nấm actinomycosis và bệnh sán máng.

Về mặt lâm sàng, tỷ lệ bênh nhân không có triệu chứng chiếm $13 \%$ đến $55 \%$. Biểu hiện lâm sàng với tam chứng cổ điển là khó thở khi gắng sức, tím và ngón tay chân hình dùi trống [3]. Cả ba dấu hiệu này đều có trong trường hợp lâm sàng mà chúng tôi gặp. Triệu chứng hay gặp nhất là khó thở khi gắng sức, gặp trong $31 \%$ đến $67 \%$ trường hợp. Mức độ khó thở tùy thuộc vào luồng thông nhiều hay ít, phần lớn bệnh nhi thích nghi khá tốt tình trạng thiếu oxy. Biểu hiện lâm sàng có liên quan với 
kích thước của khối dị dạng, dị dạng thông động tĩnh mạch nhỏ hơn $2 \mathrm{~cm}$ thấy trên Xquang phổi thường không gây nên triệu chứng lâm sàng. Nghiên cứu hồi cứu trên 105 bệnh nhân bị dị dạng thông động tĩnh mạch của Stringer và cộng sự cho thấy có $27 \%$ trẻ xuất hiện tím lúc sinh và trẻ nhũ nhi, $25 \%$ phát hiện tím ở trẻ lớn và $10 \%$ ở trẻ vị thành niên [6]. Ngoài tam chứng cổ điển ra, bệnh nhân có thể có những triệu chứng khác như nhức đầu, chóng mặt, liệt nhẹ, ngất, lú lẫn. Khi có triệu chứng chảy máu cam hay đi phân đen, dấu dãn mạch niêm mạc và các triệu chứng thần kinh thường gặp trong bệnh cảnh có kèm bệnh lý dãn mạch xuất huyết di truyền. Thăm khám lâm sàng, tiếng thổi ở vị trí di dạng có thể gặp trong $46 \%$ trường hợp [4]. Tiếng thổi nghe rõ hơn trong kỳ thở vào và giảm đi trong kỳ thở ra hay khi làm nghiệm pháp Valsalva do giảm lượng máu tĩnh mạch trở về phổi.

Biến chứng do dị dạng thông động mạch phổi gây ra bao gồm co giật, đau đầu Migraine, đột qụy, abscess não, tràn khí màng phổi, ho ra máu nặng, tăng áp phổi, suy tim sung huyết, thiếu máu, đa hồng cầu, viêm nội tâm mạc nhiễm khuẩn. Trong một nghiên cứu gần đây cho thấy tỉ lệ bệnh nhân có biến chứng đột quỵ là $11.3 \%$ và abscess là $9 \%$ [1],[7]. Đây đôi khi là triệu chứng làm cho bệnh nhân phải nhập viện và phát hiện ra bệnh lý dị dạng thông động tĩnh mạch phổi như trường hợp chúng tôi gặp.

Xquang phổi không chuẩn bị có giá trị trong việc phát hiện dị dạng thông động tĩnh mạch phổi, 98\% bệnh nhân có biểu hiện bất thường trên phim, đặc điểm tổn thương là khối mờ đồng nhất hình bầu dục kích thước 1 $5 \mathrm{~cm}, 2 / 3$ trường hợp gặp ở thùy dưới của phổi [3].

Siêu âm tim qua thành ngực cho kết quả bình thường. Siêu âm cản quang có độ nhạy $100 \%$ trong phát hiện luồng thông phải trái. Cách thực hiện khá đơn giản, bằng cách bơm 5-10 ml nước muối sinh lý có tạo vi bọt khí bằng rung lắc mạnh vào tĩnh mạch ngoại biên, trong khi vừa siêu âm đánh giá các buồng tim, từ đó đánh giá luồng thông phải trái ở phổi với biểu hiện vi bọt khí xuất hiện chậm ở nhĩ trái sau 3 chu kỳ bóp của tim sau khi đã vào buồng tim phải. Để đánh giá luồng thông, người ta chia ra làm 4 mức độ khác nhau: độ 1: không thấy vi bọt khí qua nhĩ trái; độ 1: vi bọt khí qua ít < 20 bọt khí; độ 2 : vi bọt khí qua vừa; độ 3 : vi bọt khí qua nhiều, thấy cản quang chiếm toàn bộ nhĩ trái và thất trái [5],[8]. Nghiệm pháp này dương tính chứng tỏ có luồng thông phải trái do dị dạng thông động tĩnh mạch phổi hoặc dò động mạch phổi vào nhĩ trái.

Tiêu chuẩn vàng để chẩn đoán xác định là chụp $\mathrm{CT}$ scan có cản quang khảo sát động tĩnh mạch phổi hoặc thông tim đánh giá trực tiếp động tĩnh mạch phổi.
Điều trị có thể bằng thông tim làm tắt mạch, phẩu thuật hoặc điều trị nội ở một số trường hợp dị dạng thông động tĩnh mạch phổi nhỏ và lan tỏa. Chỉ định thông tim can thiệp làm tắt mạch khi bệnh nhân có dấu hiệu tổn thương lớn dần lên, biến chứng tắt mạch như đột quy, giảm oxy máu có triệu chứng hoặc động mạch đến lớn hơn $3 \mathrm{~mm}$ [8]. Phẩu thuật bao gồm cắt bỏ thùy phổi, phân thùy hoặc cắt đường dò.

\section{KẾT LUẬN}

- Dị dạng thông động tĩnh mạch phổi là một bệnh hiếm gặp ở trẻ em, biểu hiện lâm sàng với tam chứng cổ điển là khó thở khi gắng sức, tím và ngón chân tay hình dùi trống gần giống như bệnh cảnh tim bẩm sinh có tím.

- Cần lưu ý để phá hiện sớm tình trạng di dạng thông động tĩnh mạch phổi để điều trị bởi vì bệnh có thể gây nên những biến chứng do luồng thông phải trái tạo nên, đặc biệt là đột quỵ và abscess não.

- Siêu âm cản quang là một xét nghiệm khá đơn giản, dễ làm với độ nhạy $100 \%$ để phát hiện ra luồng thông phải trái ở phổi.

\section{TÀI LIÊU THAM KHẢO}

1. C.L. Shovlin, J.S.R. Gibbs and J.E. Jackson. Management of pulmonary arteriovenous malformations in pulmonary hypertensive patients: a pressure to embolise?. Eur Respir Rev 2009; 18: 111, 4-6.

2. Hassan Mottaghi et all. Congenital pulmonary arteriovenous malformation: a rare cause of cyanosis in childhood. Pan African Medical Journal 2009; 3:12.

3. I Khurshid, G H Downie. Pulmonary arteriovenous malformation. Postgrad Med J 2002;78:191-197.

4. James R. Gossage and Ghassan Kanj. Pulmonary Arteriovenous Malformations. A State of the Art Review. Am J Respir Crit Care Med 1998; Vol 158. pp 643-661.

5. P. Gazzaiga et all. Contrast echocardiography for pulmonary arteriovenous malformations screening: does any bubble matter?. European Journal of Echocardiography 2009; 10, 513-518.

6. Richard L. Prager, Kenneth H. Law and Harvey W. Bender. Ateriovenous fistula of the lung. Ann Thorac Surg 1993; 36: 231-239.

7. Robert L. Thompson. Stephen M. Cattaneo and James Barnes. Recurrent brain abscess: Manifestation of pulmonary arteriovenous fistula and hereditary hemorrhagic telangiectasia. Chest 1997; 72:5

8. Sharifah A I M, Jasvender K, Rus A A. Pulmonary arteriovenous malformation: a rare cause of cyanosis in a child. Singapore Med J 2009; 50(4): e127-e129. 